\title{
AOR
}

Selected Papers of \#AolR2020:

The $21^{\text {st }}$ Annual Conference of the Association of Internet Researchers

Virtual Event / 27-31 October 2020

\section{THE VIRTUAL CENSUS 2.0: A CONTINUED INVESTIGATION ON THE REPRESENTATION OF GENDER, RACE AND AGE IN VIDEOGAMES}

\author{
Annie Harrisson \\ Concordia University \\ Jessie Marchessault \\ Concordia University \\ Sâmia Pedraça \\ Concordia University \\ Shawn Suyong Yi Jones \\ Concordia University \\ Mia Consalvo \\ Concordia University

\section{Introduction}

In 2009, Williams et al. examined the representation of characters in the United States' 100 top-selling videogames of 2005 in "The Virtual Census: Representation of Gender, Race and Age in Videogames". Their results highlighted the overrepresentation of characters that are White, adult and male compared to characters of other races, genders, or age groups. A decade later, we revisit key questions addressed in the original research to examine how these representations have changed over time.

\section{Research Questions}

Our study revisits the following three research questions:

- RQ1: How frequently are different gender, race and age groups represented in games?

- RQ2: Is there a difference between groups' appearance in primary and secondary roles? 
- RQ3: Is there a difference in characters' social group representation between games with different ESRB ratings?

While the first research question considers the overall frequency in which these social categories appear in videogames, the second and third questions address the context in which these representations take place. Specifically, RQ2 looks at the representation of the three social groups in the context of character playability and RQ3 focuses on representation within different ESRB ratings. To Williams et al.'s inquiry, we added a fourth question that takes into account the intersections of the three social groups:

- RQ4: How does character playability relate to the intersection of demographic characteristics and game rating?

This intersectional approach allows us to make visible the gaps in representation of specific groups defined by multiple identities.

\section{Methods}

This study examines 8,135 characters observed in a sample of 100 videogames. The sample of games was drawn from the United Kingdom's 100 top-selling boxed videogames of 2017 according to UKIE and GfK Chart-Track. This list consists of PlayStation 4, Xbox One, and Nintendo Switch games, as well as a limited number of PC and Nintendo 3DS titles. The list includes both games that were launched in 2017 and years prior that have consistently maintained high sales figures through online features and DLCs. Following the method of the original study, mobile and/or free-to-play titles were excluded from our analysis. Members of the research team played and recorded the opening cinematic scene, as well as the first 15 minutes of gameplay for each game. Given the study's focus on human representation and its impact on social groups, only the 7,043 human characters of the 8,135 total characters coded were considered for analysis.

\section{Preliminary Findings}

The following discusses each social category separately in relation to RQ1, 2 and 3 . The preliminary analyses show that, similarly to the 2009 study, most characters proportionally are White, male, and adult.

Nevertheless, the overall proportion of female characters has nearly doubled from $13 \%$ in 2005 to $22 \%$ in 2017 . When examining this increase in relation to playability, however, female characters accounted for $15 \%$ of all primary roles and $13 \%$ of secondary roles in 2005 , compared to $16 \%$ of primary roles and $22 \%$ of secondary roles in 2017 . So, while the proportion of overall female characters nearly doubled, this increase was primarily due to non-playable secondary roles. In regards to' ESRB rating, the results show a significant increase in the presence of female characters in both Teen $(T)$ and Mature (M) rated games, while there was no significant change in Everyone $(E)$ and Everyone +10 $(E+10)$ games. 
With respect to race, the proportion of POC characters significantly increased from $17 \%$ to $20 \%$ between the two studies. Specifically, Asian/Pacific Islanders (API) and biracial characters significantly increased while Black and Hispanic characters did not significantly change. For RQ2, the probability of a Black character being playable increased over time while the other racial groups saw no significant change; White characters still occupied a higher proportion of the secondary non-playable roles in both years. Finally, there was a significant increase in biracial characters in E games, API in T games, and White in $\mathrm{M}$ games, while $\mathrm{T}$ and $\mathrm{M}$ games both saw a significant decrease in Black and Hispanic characters.

Looking at age, the present study found no significant change in child and elderly representation across time. However, the proportion of adult characters did significantly increase, while that of teen characters decreased. In terms of playability, the probability of an adult character being primary in 2017 increased, while all other age categories had no significant change. In general, the proportion of adult characters has increased noticeably in E and E+10 rated games from 2005 to 2017. Meanwhile, the representation of elderly characters has stayed nearly the same across all categories, with the exception of $E+10$, which showed a slight increase.

Finally, RQ4 concerns the intersection of gender, race, and age relative to character playability and ESRB rating. Biracial male and female characters have significantly higher model-predicted probabilities of being playable compared to their White counterparts. Conversely, White characters of both genders generally had lower probabilities. The model showed no significant interaction between race and gender, even though the interaction coefficients are fairly large. This non-significance is possibly due to low statistical power when characters are simultaneously categorized by race and gender. Correspondingly, we noticed a trend in the model predictions consistent with an intersectional effect. Black female characters, who had the lowest probability of being playable across all rating categories, were much less likely than Black males to be playable. Conversely, API female characters consistently had a higher predicted probability than API males of being playable across ESRB ratings and ages.

\section{Significance of findings}

Though discussions on "race", "diversity" and "inclusiveness" in videogames have been raised at industry events such as the annual Game Developers Conference (GDC), studies have shown that representations of race and ethnicity have barely shifted in recent years (Waddell et. al. 2014). Given the media's influence to shape a consumer's worldview, there is growing concern over the lack of diversity in the representation of videogame characters, which could have significant social impacts on players-for example, normalizing power imbalances and marginalizing certain groups (Gerbner et al. 1994; Harwood and Anderson 2002). In conducting a virtual census of the human characters present in the best-selling UK games of 2017, the researchers hope to bring an awareness to the continued lack of diverse representation of videogame characters, while simultaneously underlining the positive changes and trends that are slowly emerging due to the pressure of a more diverse and socially conscious gaming community. 


\section{Works Cited}

Gerbner, G. et al. "Growing Up with Television: The Cultivation Perspective." Media Effects: Advances in Theory and Research, edited by J. Bryant and D. Zillman, Lawrence Erlbaum Associates, 1994, pp. 17-41.

Harwood, J. and K. Anderson. "The Presence and Portrayal of Social Groups on Primetime Television." Communication Reports, vol. 15, no. 2, 2002, pp. 81-97.

Williams, Dmitri, et al. "The virtual census: Representations of gender, race and age in video games." New Media \& Society, vo. 11, no. 5 2009, pp. 815-834.

Waddell, T. F. et al. "White man's virtual world: A systematic content analysis of gender and race in massively multiplayer online games." Journal For Virtual Worlds Research, vol. 7, no. 2, 2014. 